\title{
ESTIMATING THE COST OF IMPROVING QUALITY IN ELECTRICITY DISTRIBUTION: A PARAMETRIC DISTANCE FUNCTION APPROACH
}

\section{October 2012}

Tim J. Coelli (University of Queensland), Axel Gautier (CREPP, HEC Management School University of Liège), Sergio Perelman (CREPP, HEC Management School University of Liège) and Roxana Saplacan-Pop (Electricité de France)

\begin{abstract}
The quality of electricity distribution is being more and more scrutinized by regulatory authorities, with explicit reward and penalty schemes based on quality targets having been introduced in many countries. It is then of prime importance to know the cost of improving the quality for a distribution system operator. In this paper, we focus on one dimension of quality, the continuity of supply, and we estimated the cost of preventing power outages. For that, we make use of the parametric distance function approach, assuming that outages enter in the firm production set as an input, an imperfect substitute for maintenance activities and capital investment. This allows us to identify the sources of technical inefficiency and the underlying trade-off faced by operators between quality and other inputs and costs. For this purpose, we use panel data on 92 electricity distribution units operated by ERDF (Electricité de France - Réseau Distribution) in the 2003-2005 financial years. Assuming a multi-output multi-input translog technology, we estimate that the cost of preventing one interruption is equal to $10.7 €$ for an average DSO. Furthermore, as one would expect, marginal quality improvements tend to be more expensive as quality itself improves.
\end{abstract}

Keywords: electricity distribution; parametric distance function; shadow price of quality.

Corresponding author:

Sergio Perelman

CREPP, HEC Management School

University of Liège

Bd. du Rectorat 7 (B31)

4000 Liège, Belgium

Phone: +32 43663098

Fax: +3243669318

Email: sergio.perelman@ulg.ac.be 


\section{INTRODUCTION}

The frequency and the duration of power outages are the two key measures of quality that electricity distribution utilities pay particular attention to. Other than the direct costs of outages, represented by opportunity costs and repair expenditures, there is also a regulatory cost as regulators more and more impose bonuses and penalties based on service quality performance. This is for instance the case in France, Germany, Italy and the UK. To prevent outages and these related costs, operators have two main possibilities, either to increase maintenance or to make new investments, e.g. replace overhead lines by underground lines.

In this paper, we estimate the marginal cost of preventing an outage for a distribution system operator (DSO), what we call hereafter the shadow price of quality. This shadow price represents the additional operational or capital expenditure that the DSO must incur in order to reduce the number of outages by one. This information is of particular importance for regulatory purpose as both the marginal benefit and the marginal cost of supplying additional quality are necessary to determine the welfaremaximizing level of service quality (Sappington, 2005).

To estimate the shadow price of quality, we make use of the parametric distance function approach. We apply the same approach as Färe et al. (1993) but instead of considering outages as an undesirable output, we assume that they enter in the firm production set as an input i.e., that outages are an imperfect substitute for maintenance activities and investment. Therefore, following Growitsch et al. (2009), we postulate that the corresponding distance function is input oriented. This allows us to identify the underlying trade-off faced by operators, between quality and other inputs and costs.

We estimate a flexible translog multi-output multi-input technology. On the output side, we chose a specification that takes into account the main output dimensions of the electricity distribution activity: i) the number of customers; ii) the surface area served and; iii) the GWh of electricity distributed. On the input side, the three dimensions retained are: i) operational expenditures; ii) capital; and iii) quality, represented by the number of interruptions (longer than 3 minutes in duration). We use for computation purposes, a stochastic frontier approach (SFA) as well as a parametric (deterministic) linear programming approach (PLP). Both approaches give similar results, on average. 
With the SFA approach we can take into account the influence of random noise - but we find that the monotonicity requirements are not satisfied for all observations. We have thus developed a methodology to integrate the monotonicity constraints in a simple and convenient way using the deterministic PLP approach. To estimate the parameters of the production function, we use panel data on 92 electricity distribution units operated by ERDF (Electricité de France - Réseau Distribution) in France in the 2003-2005 financial years. Compared with similar studies, we have access to very comprehensive and comparable data, in particular on the value of capital. ${ }^{1}$

We derive from the underlying production technology the shadow prices for the quality (outages), that is the marginal rate of substitution between quality and the other inputs. For France, the average shadow price of quality is estimated to be $10.7 €$, meaning that it costs the DSO an additional $10.7 €$ to prevent one interruption. Our results show that the estimated shadow price of quality varies substantially: from $1.28 €$ to $69.2 €$ among the DSOs. Furthermore, as one would expect, marginal quality improvements tend to be more expensive as a network approaches $100 \%$ reliability i.e. the cost of quality function is a convex function.

We also estimate the distance function elasticities with respect to inputs and outputs for each DSO. These elasticities can be used to determine the main cost drivers of the operators. Results indicate that, when customer density is low, the main cost driver is the number of clients while electricity delivered can be increased at little cost. When customer density is high, increasing the number of clients and the electricity delivered requires both a substantial input expansion. Finally, our models completely benchmark the French DSO taking the quality into account, an important exercise since the regulators have now started to use explicit benchmarking methods to regulate the energy distribution companies (see Farsi et al., 2007 for a description).

The remainder of the paper is organized as follows. In Section 2 we survey the literature on benchmarking analyses in electricity distribution including service quality while Section 3 describes the electricity distribution sector in France. Sections 4 and 5 present the methodology and the data used in estimation, respectively. In Section 6 we report the main results of this study and in Section 7 we draw some conclusions. 


\section{RELATED LITERATURE}

Most benchmarking analyses in electricity distribution have involved models that incorporate standard output characteristics, such as energy supplied (in GWh), number of customers and network size (e.g., service area or network length). For example, see the literature review in London Economics (1999) and Jamasb and Pollitt (2001). Very few studies have included quality of service measures in these models. Some exceptions are the studies by Giannakis et al. (2005), Growitsch et al. (2009), Coelli et al. (2007) and Jamasb et al. (2010).

Giannakis et al (2005) use data envelopment analysis (DEA) methods to measure technical efficiency (TE) and total factor productivity growth (TFP) in 14 UK distribution companies over the $1991 / 92$ to $1998 / 99$ period. The DEA method is used to estimate a non-parametric input distance function that involves three output variables (energy supplied, customers and network length). Four models involving different input sets are considered: (i) operating expenditure (OPEX); (ii) total expenditure (TOTEX); (iii) number of interruptions (NINT) and total time lost due to interruptions (TINT); and (iv) TOTEX, NINT and TINT. They find that the TE scores of the various models are positively (but not perfectly) correlated, and that the TE scores rise when the NINT and TINT quality variables are added to the TOTEX model (a result that is to be mathematically expected when variables are added to a DEA model). ${ }^{2}$

Growitsch et al (2009) use stochastic frontier analysis (SFA) methods to estimate an input distance function using data on 505 electricity distribution utilities from eight European countries in the 2002 financial year. Their models contain two output variables (energy supplied and customers) and either one input variable (TOTEX) or two input variables (TOTEX and TINT). They use the Battese and Coelli (1995) SFA model to investigate the effects of customer density (customers per network $\mathrm{km}$ ) and country (using dummy variables) upon technical efficiency scores. They find that the inclusion of the quality variable reduces TE for all but the large firms, plus they find that the TE scores from the two models are significantly negatively correlated, both findings being in contrast to those of Giannakis et al (2005).

Jamasb et al. (2010) estimate the marginal cost of quality improvements of $12 \mathrm{UK}$ distribution companies for the period 1995-2003. For that, they run fixed-effect estimations of the link between the cost of electricity distribution (identified with 
TOTEX, OPEX or CAPEX) and a series of cost drivers including the energy delivered, the network length, the network energy losses, the customer minutes lost and a time trend. They found that the marginal cost of quality is positive and, on average, equal to 25.6 pence per minute lost. This estimated marginal cost of improving quality is larger than the penalty set by the regulator for lower delivered quality. Consequently, the UK quality of service regulation does not provide enough incentives to increase the quality as the firms are better off paying the fine. Finally, the marginal cost of improving quality increases with the quality delivered, as expected.

The above studies are to be commended for introducing quality variables into these benchmarking models. However, these studies contain some shortcomings. First, they all make use of TOTEX measures which contain capital expenditure (CAPEX) measures which need not reflect the actual amount of capital services consumed in a particular year. Second, the UK studies suffer from small sample size problems while the intercountry study suffers from difficulties associated with deflating monetary values of TOTEX in order to obtain comparable measures of implicit input usage in each country. Last, inter-country comparisons are often unable to properly take into account country heterogeneity effects, such as differences in the perimeter of activity.

In the current study we aim to address these problems by making use of a detailed database on the activities of 92 electricity distribution units operated by ERDF Réseau Distribution in France in the 2003-2005 financial years. With these data we thus avoid the small sample size problem and the international comparability problem. Furthermore, we also have access to comprehensive and comparable data on the value of capital items, measured at its gross value, so we can avoid the need to use CAPEX to measure capital input services. ${ }^{3}$ With this unique dataset, we are able to distinguish three inputs: OPEX, capital and interruptions, better reflecting the choice made by the operators. We are thus able to identify the underlying trade-off faced by operators and, in particular, the trade-off between quality and other inputs.

\section{ELECTRICITY DISTRIBUTION IN FRANCE}

In France, most electricity distribution grids are owned by municipalities, individually or grouped in communities. To organize the public service of electricity distribution, municipalities either delegate the network management to a third party DSO within the 
framework of a long-term concession contract or organize the service themselves. Most of the municipalities delegate the management of their network to $\mathrm{ERDF}^{4}$, a subsidiary of EDF, the historical electricity operator which is now publicly listed company but with a majority of the shares owned by the French State. ERDF covers more than $95 \%$ of the territory while the remaining part is covered by local public companies.

The concession contracts define the rights and obligations of the distributor regarding quality of supply, customers' connections and environmental conditions. Public service requirements are the same all over the country and the contracts follow a similar model. The DSO is remunerated by the tariff applied to final users, which is supposed to cover operating costs and investments. This tariff is the same for all the concessions (one single price for all the customers in France) and for all DSOs. The rates for the use of public electricity grids, including transmission and distribution networks, are set periodically by the French Regulator, the CRE (Commission de Régulation de l'Energie).

ERDF has organized its network in 93 local distribution units. These units, known as Centres, are grouped in 23 URE (Unité Réseau Electrique) and further aggregated in 8 regions. During the sample period, Centres were autonomous (within limits) for taking decisions regarding capital and operational expenditures. In 2006, the company was reorganized and the decision making powers moved to the URE, with the Centres remaining as administrative units.

Quality of electricity distribution has multiple aspects: the quality of the commercial service, the voltage quality and the continuity of supply being the most closely scrutinized by regulatory authorities. ${ }^{5}$ The quality of electricity distribution is regulated by the CRE. For the continuity of supply (our main focus in this paper), the CRE measures quality by the minutes of interruption from which a series of exceptional events are removed (the so-called “criterion B"). During our sample period (2003-2005), the quality of electricity distribution, measured by the frequency of interruption per customer (SAIFI) or the total minutes of interruption (SAIDI) has improved slightly (see Figure 1). ${ }^{6}$ It can be observed that, in 2006, both the frequency and the number of interruptions are higher than their 2000 level. As quality is a major concern, the regulator has introduced in 2009 an incentive mechanism based on a quality target with rewards/penalties set according to the fulfilment of the objectives. In the current mechanism, the penalty for each minute of interruption across all customers above the 
target (55 minutes/client/year in 2009) is 4 million $€$ per minute with a cap on the total amount to be collected. To our knowledge, this incentive mechanism was not yet in place during the sample period.

Figure 1: Quality of electricity distribution (2000-2006)

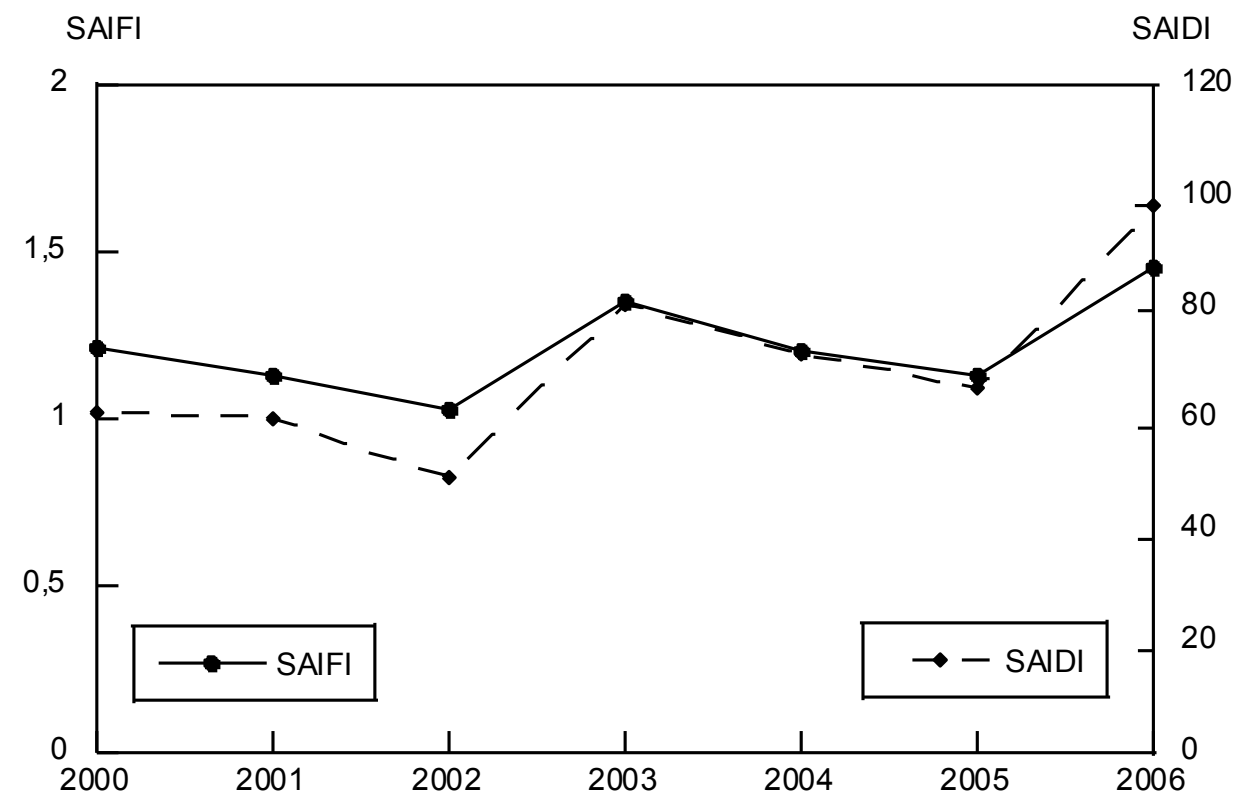

\section{METHODOLOGY}

We model the production process of a DSO using a multi-input, multi-output distance function. The distance function is input-oriented. In addition to the traditional inputs (capital and operating expenses), we add the number of interruptions (a quality variable) as a third input. That is, interruptions are introduced as a bad input (see Giannakis et al., 2005 and Growitsch et al., 2009). The logic is that the operators can substitute between regular inputs (labour, capital etc.) and the inconvenience faced by the customers (interruptions). The rational operator will look at the "price of interruptions" (e.g., the penalty imposed by the regulator) and compare it with the price of other inputs (e.g., labour) before deciding upon the optimal (cost minimising) mix of inputs to use.

If the production technology (frontier) is known (which is rarely the case) we can measure the distance that each data point (firm) lies below the frontier by calculating the amount by which the input vector $(\mathbf{x})$ can be proportionally reduced while holding the output vector $(\mathbf{y})$ constant. That is, for each data point $(\mathbf{x}, \mathbf{y})$ we seek to find the biggest possible value of the scalar $\rho$ such that $(\mathbf{x} / \rho, \mathbf{y})$ remains within the feasible 
production set bounded by the frontier. $\rho$ is the technical efficiency score of the firm meaning that a firm can reduce input usage by $1 / \rho$ and still produce the same output vector.

In reality, the production frontier is rarely known. Instead it is estimated using sample data on a number of firms. This generally involves fitting an empirical frontier that aims to minimize these distances so that the frontier is a "tight-fit" to the data. In this paper we use parametric methods to estimate an input distance function.

The input distance function may be defined on the input set, $L(\mathbf{y})$, as:

$$
D_{\mathbf{I}}(\mathbf{x}, \mathbf{y})=\max \{\rho:(\mathbf{x} / \rho) \in L(\mathbf{y})\},
$$

where the input set $L(\mathbf{y})$ represents the set of all input vectors, $\mathbf{x} \in R_{+}^{\mathbf{K}}$, which can produce the output vector, $\mathbf{y} \in R_{+}^{\mathbf{M}}$. That is,

$$
L(\mathbf{y})=\left\{\mathbf{x} \in R_{+}^{\mathbf{K}}: \mathbf{x} \text { can produce } \mathbf{y}\right\} .
$$

$D_{\mathbf{I}}(\mathbf{x}, \mathbf{y})$ is non-decreasing, positively linearly homogeneous and concave in $\mathbf{x}$, and increasing in $\mathbf{y}$. The distance function will take a value which is greater than or equal to one if the input vector, $\mathbf{x}$, is an element of the feasible input set, $L(\mathbf{y})$. That is, $D_{\mathbf{I}}(\mathbf{x}, \mathbf{y}) \geq 1$ if $\mathbf{x} \in L(\mathbf{y})$. Furthermore, the distance function will take a value of unity if $\mathbf{x}$ is located on the inner boundary of the input set.

\section{The Translog input distance function}

Following Coelli et al (2003), a translog input distance function for the case of $M$ outputs and $K$ inputs is specified as

$$
\begin{aligned}
& \ln D_{\mathrm{i}}=\alpha_{0}+\sum_{\mathrm{m}=1}^{\mathrm{M}} \alpha_{\mathrm{m}} \ln y_{\mathrm{mi}}+\frac{1}{2} \sum_{\mathrm{m}=1}^{\mathrm{M}} \sum_{\mathrm{n}=1}^{\mathrm{M}} \alpha_{\mathrm{mn}} \ln y_{\mathrm{mi}} \ln y_{\mathrm{ni}}+\sum_{\mathrm{k}=1}^{\mathrm{K}} \beta_{\mathrm{k}} \ln x_{\mathrm{ki}} \\
& +\frac{1}{2} \sum_{\mathrm{k}=1}^{\mathrm{K}} \sum_{l=1}^{\mathrm{K}} \beta_{\mathrm{k} l} \ln x_{\mathrm{ki}} \ln x_{l \mathrm{i}}+\sum_{\mathrm{k}=1}^{\mathrm{K}} \sum_{\mathrm{m}=1}^{\mathrm{M}} \delta_{\mathrm{km}} \ln x_{\mathrm{ki}} \ln y_{\mathrm{mi}}+\sum_{j=1}^{J} \theta_{j} z_{j i}, \quad \mathrm{i}=1,2, \ldots, \mathrm{N},
\end{aligned}
$$

where the $z_{j}(j=1, . ., J)$ denote environmental factors and $i$ the $i$-th firm in the sample of $N$ firms. $^{7}$ Note that to obtain the frontier surface (i.e., the transformation function) one would set $D_{i}=1$, which implies the left hand side of equation (3) is equal to zero. 
Environmental factors are assumed to have a direct linear influence on the production structure. In other words, potentially each firm faces a different production frontier at each period given the effect of $z_{j}$ factors on the technology (Coelli et al., 1999).

Imposing homogeneity of degree +1 in inputs and rearranging we obtain

$$
\begin{gathered}
\ln \left(1 / x_{K i}\right)=\alpha_{0}+\sum_{\mathrm{m}=1}^{\mathrm{M}} \alpha_{\mathrm{m}} \ln y_{\mathrm{mi}}+\frac{1}{2} \sum_{\mathrm{m}=1}^{\mathrm{M}} \sum_{\mathrm{n}=1}^{\mathrm{M}} \alpha_{\mathrm{mn}} \ln y_{\mathrm{mi}} \ln y_{\mathrm{ni}}+\sum_{\mathrm{k}=1}^{\mathrm{K}-1} \beta_{\mathrm{k}} \ln x_{\mathrm{ki}}^{*} \\
+\frac{1}{2} \sum_{\mathrm{k}=1}^{\mathrm{K}-1} \sum_{l=1}^{\mathrm{K}-1} \beta_{\mathrm{k} l} \ln x_{\mathrm{ki}}^{*} \ln x_{l \mathrm{i}}^{*}+\sum_{\mathrm{k}=1}^{\mathrm{K}-1} \sum_{\mathrm{m}=1}^{\mathrm{M}} \delta_{\mathrm{km}} \ln x_{\mathrm{ki}}^{*} \ln y_{\mathrm{mi}}+\sum_{j=1}^{J} \theta_{j} z_{j i}-\ln D_{\mathrm{i}}, \quad \mathrm{i}=1,2, \ldots, \mathrm{N},
\end{gathered}
$$

where $x_{\mathrm{ki}}^{*}=x_{\mathrm{ki}} / x_{\mathrm{Ki}}$.

The restrictions required for homogeneity of degree +1 in inputs are

$$
\sum_{\mathrm{k}=1}^{\mathrm{K}} \beta_{\mathrm{k}}=1
$$

and

$$
\sum_{l=1}^{\mathrm{K}} \beta_{\mathrm{k} l}=1, \mathrm{k}=1,2, \ldots, \mathrm{K}, \text { and } \sum_{\mathrm{k}=1}^{\mathrm{K}} \beta_{\mathrm{km}}=1, \mathrm{~m}=1,2, \ldots, \mathrm{M}
$$

and those required for symmetry are

$$
\alpha_{\mathrm{mn}}=\alpha_{\mathrm{nm}}, \mathrm{m}, \mathrm{n}=1,2, \ldots, \mathrm{M} \text {, and } \beta_{\mathrm{k} l}=\beta_{l \mathrm{k}}, \mathrm{k}, l=1,2, \ldots, \mathrm{K} \text {. }
$$

Shadow prices

We make use of the methods described in Grosskopf et al (1995), Morrison Paul and Nehring (2005), and others to derive measures of the input shadow prices. We obtain ratios of shadow prices from the ratios of derivatives of the input distance function:

$$
\frac{w_{\mathrm{ki}}}{w_{l \mathrm{i}}}=\frac{\partial D_{\mathrm{i}} / \partial x_{\mathrm{ki}}}{\partial D_{\mathrm{i}} / \partial x_{l \mathrm{i}}}
$$

for the case of inputs, and

$$
\frac{p_{\mathrm{mi}}}{p_{\mathrm{ni}}}=\frac{\partial D_{\mathrm{i}} / \partial y_{\mathrm{mi}}}{\partial D_{\mathrm{i}} / \partial y_{\mathrm{ni}}}
$$

for the case of outputs. 
These ratios measure the curvature of the estimated distance functions and can be interpreted as marginal rates of substitution between inputs and between outputs. Cost minimizing behaviour by the firm implies that the marginal rate of substitution between inputs is equal to the price ratio. Thus, assuming cost minimization, we can interpret the ratios of derivatives as shadow price ratios. ${ }^{8}$ Furthermore, if the price of one input is known, it is possible to derive the shadow price from the shadow price ratio. We are particularly interested in the shadow price of quality that is an estimate of the cost of preventing one interruption. As the price of OPEX is equal to $1 €$, the shadow price of quality (expressed in OPEX) can be immediately derived from the shadow price ratio.

In order to compute ratios of shadow prices, we compute input distance partial elasticities with respect to inputs:

$$
s_{\mathrm{ki}}=\frac{\partial \ln D_{\mathrm{i}}}{\partial \ln x_{\mathrm{ki}}}=\beta_{\mathrm{k}}+\sum_{\mathrm{l}=1}^{\mathrm{K}} \beta_{\mathrm{k} l} \ln x_{l \mathrm{i}}+\sum_{\mathrm{m}=1}^{\mathrm{M}} \delta_{\mathrm{km}} \ln y_{\mathrm{mi}},
$$

and with respect to outputs:

$$
r_{\mathrm{mi}}=\frac{\partial \ln D_{\mathrm{i}}}{\partial \ln y_{\mathrm{mi}}}=\alpha_{\mathrm{m}}+\sum_{\mathrm{n}=1}^{\mathrm{M}} \alpha_{\mathrm{mn}} \ln y_{\mathrm{ni}}+\sum_{\mathrm{k}=1}^{\mathrm{K}} \delta_{\mathrm{km}} \ln x_{\mathrm{ki}}
$$

These elasticities have also a direct interpretation as shadow shares. Shares of inputs in total input, for $s_{\mathrm{ki}}$, and shares of outputs in total output, for $r_{\mathrm{mi}}$. Moreover, combining $r_{\mathrm{mi}}$ we compute scale elasticities at each point:

$$
e_{\mathrm{i}}=\sum_{\mathrm{m}=1}^{\mathrm{M}} r_{\mathrm{mi}}
$$

With $e_{\mathrm{i}}>-1, e_{\mathrm{i}}=-1$ and $e_{\mathrm{i}}<-1$ indicating increasing, constant or decreasing returns to scale, respectively (Färe and Primont, 1995).

Furthermore, a well-behaved production function must satisfy some desirable properties, among them monotonicity and curvature conditions. Monotonicity implies that the input distance function analysed here has to be non-decreasing in inputs $\left(s_{\mathrm{ki}} \geq 0\right)$ and non-increasing in outputs $\left(r_{\mathrm{mi}} \leq 0\right)$ (Färe and Primont, 1995). Curvature conditions imply that the input distance function satisfy convexity in outputs and quasiconvexity in inputs. 


\section{Stochastic frontier analysis (SFA)}

To estimate the model using SFA methods we replace the distance term with an error term that has two i.i.d. components. That is, we set $-\ln D_{\mathrm{i}}=v_{\mathrm{i}}-u_{\mathrm{i}}$, where $v_{\mathrm{i}} \sim \mid N\left(0, \sigma_{v}^{2}\right)$ is a symmetric error to account for data noise and the $u_{\mathrm{i}} \sim \mid N^{+}\left(0, \sigma_{u}^{2}\right)$ is a one-sided error to account for technical inefficiency (TE), which is assumed to have a half-normal distribution. The technical efficiency score for the $i$-th firm is predicted using the conditional expectation: $E\left[\exp \left(-u_{i} \mid v_{i}-u_{i}\right)\right]$, which takes a value between 0 and 1 . The model is estimated using maximum likelihood (ML) methods. Note that prior to estimation the variance parameters, $\sigma_{v}^{2}$ and $\sigma_{u}^{2}$ are re-parameterised as $\gamma=\sigma_{u}^{2} /\left(\sigma_{u}^{2}+\sigma_{v}^{2}\right)$ and $\sigma^{2}+\sigma_{v}^{2}=\sigma_{u}^{2}+\sigma_{v}^{2}$ for computational convenience. ${ }^{1}$

Unfortunately, we are unable to impose the monotonicity conditions on the SFA estimation using traditional econometric techniques. The main reason is that these conditions cannot be introduced as simple restrictions on parameters. As a consequence, the unrestricted estimations can potentially show monotonicity and curvature violations at specific data points. In other words, incorrect computed values for shadow shares and shadow prices ratios at particular points. ${ }^{9}$ This is particularly the case in this study because the quality input has a particularly low average input share (less than 5\%).

\section{Parametric linear programming (PLP)}

In this paper, we proceed in two steps. After verifying that SFA results satisfy monotonicity restrictions for average values but not for extreme points, we recomputed the input distance function using a parametric linear programming approach (PLP) and adding monotonicity constraints. The PLP is a deterministic approach, it ignores the effect of unobserved variables, but monotonicity restrictions can be included easily. As we are interested in computing the shadow price of quality for each observation, it is essential to have the monotonicity constraints satisfied at all points and not only for the average firm. ${ }^{10}$

\footnotetext{
${ }^{1}$ See Coelli et al (2005) for further details on the SFA methodology.
} 
Values of unknown parameters in equation (3) are obtained by using linear programming (LP) as follows:

$\operatorname{Min} \sum_{i=1}^{N} \ln D_{i}$,

subject to the constraints that:

$$
\begin{aligned}
& \ln \mathrm{D}_{\mathrm{i}} \geq 0, \quad \mathrm{i}=1,2, \ldots, \mathrm{N}, \\
& s_{\mathrm{ki}} \geq 0, \quad \mathrm{i}=1,2, \ldots, \mathrm{N}, \mathrm{k}=1,2, \ldots, \mathrm{K}, \\
& r_{\mathrm{mi}} \leq 0, \quad \mathrm{i}=1,2, \ldots, \mathrm{N}, \mathrm{m}=1,2, \ldots, \mathrm{M},
\end{aligned}
$$

as well as to the same homogeneity and symmetry constraints in (4) and (5).

As an illustration, note that the LP algorithm used to solve our model consists of 304 unknown variables (37 distance function parameters and 276 TE scores) estimated under 7 equality (homogeneity) restrictions and 1.656 inequality (monotonicity) restrictions. For this purpose we run the Linprog routine in MATLAB.

\section{DATA}

The selection and measurement of input, output and environmental variables is a key aspect of any efficiency analysis exercise. In this study we have drawn upon our knowledge of the key cost drivers in the French electricity distribution industry, along with reviewing the experiences gained in previous analyses. For example, see those studies surveyed in London Economics (1999) and Jamasb and Pollitt (2001), and more recent studies, such as Lawrence and Diewert (2006), Edvardsen et al (2006) and Jamasb et al. (2010).

\section{Output variables}

Three output variables are used in the present study: energy supplied, number of customers and the service area. The amount of energy supplied in giga-watt hours (GWH) is generally the first output variable thought of, since the aim of a distribution company is to "supply electricity to customers". Although a distribution network operator cannot normally determine the amount of electricity distributed, it has to 
ensure that all its network assets have the capacity to deliver this energy to its customers. Hence, the total amount of energy supplied may be viewed as a proxy for the load capacity of the network. The measure used in this study is gross electricity distributed (which includes losses). ${ }^{11}$

The number of customers (CUST) is also used as an output variable in our model because we believe that this variable is needed to ensure that the model does not unfairly discriminate against those operators which sell smaller amounts of energy per customer. Furthermore, a large part of distribution activities (relating to metering services, customer connections, customer calls, etc.) are directly correlated to the number of customers. Note that our measure only includes Low Voltage (LV) customers, since industrial customers who are connected to the Medium Voltage (MV) network are rather small in number.

The surface covered in square kilometres (KM2) is a measure of network dispersion. A lot of network operations, such as routine maintenance, overhaul, vegetation management for overhead lines, etc. are closely linked to the length of MV and LV lines or, indirectly, to the size of the area served. Moreover, the reliability of a distribution network and therefore the level of quality of supply is often affected by the length of feeders, in other words, by customers' density. In big cities, where the feeders are mostly short and underground, the number of outages should be lower than in less dense areas which tend to have a high proportion of overhead lines. As a consequence, the costs of repairs are expected to differ between urban and rural areas.

The net effect of using these three output variables in our model is to ensure that the key aspects of output heterogeneity are captured, so that when we conduct benchmarking comparisons using technical efficiency measures, we are conditioning on these factors and hence comparing like with like. That is, not comparing distribution units like Lille with the Southern Alps, and so on. Nevertheless, we are aware that with three output variables, we are unable to control for all environmental differences that could influence costs, such as influence of forests and mountainous terrain, ages of the assets, accessibility of lines or substations, climatic factors, etc. To mitigate this problem, we introduce control variables to explain potential differences on the production technology driven by these factors. 


\section{Input variables}

The inputs used in electricity distribution are many and varied. In terms of capital inputs there are underground and overhead lines of various voltage levels, transformers, vehicles, computers, and so on. Plus we have various types of labour - technicians, engineers, managers, etc. - plus a variety of other materials and services. One could perhaps define dozens of input variables, but degrees of freedom limitations in the production model prevent us from doing that. Instead we have chosen to define only three input variables: two monetary inputs, the capital inputs (CAP) and the non-capital inputs (OPEX) and one physical (bad) input, the number of interruptions (NINT). The bad input is considered as an imperfect substitute to the other two inputs. Monetary inputs are expressed in 2005 prices using a gross industrial commodities price deflator.

Capital is measured using gross (not depreciated) value. We have chosen gross in preference to net because we wish to avoid the situation where an operator that has conducted a lot of recent investment is labelled as inefficient because their net capital stock is high relative to others. In using this measure we implicitly make two assumptions. First we assume that asset age does not significantly affect service potential. Second we assume that all operators have assets with similar life spans and hence that annual service potential is proportional to the stock. These assumptions are arguably quite reasonable in the current study, since all the data come from a single distribution operator (ERDF) who defines and manages very similar policies for investment, operations and network asset development across the various local distribution units. $^{12}$

In terms of non-capital inputs, we use network operating expenses net of depreciation and interest as our aggregate measure of these items. These are the direct operational costs of local distribution units, excluding centralized network service support and overhead costs. These operational costs relate to day-to-day operations, such as:

- operating, developing and maintaining distribution network assets: looking after substations and overhead lines, fault repairs, remote control and dispatching, and so on;

- running connections services; 
- providing meter services and any other customer interventions;

- relations with local authorities and customers; etc.

We could have chosen to split this OPEX grouping into labour and non-labour groups, but given that labour expense dominates this category and that outsourcing is blurring the boundaries between these two categories, we decided to use a single variable.

Finally, quality is measured as the total number of interruptions (NINT) - excluding short interruptions of three minutes or less.

The total number of interruptions NINT has been calculated as follows:

NINT $=$ SAIFI $\times$ Total number of customers served.

According to the international standards relative to quality of supply, SAIFI (System Average Interruption Frequency) is the average number of sustained interruptions ( $>3$ min) experienced per customer served per year:

$$
\text { SAIFI }=\frac{\text { Total number of customer int erruptions }}{\text { Total number of customers served }} .
$$

Therefore, NINT represents the total number of outages. It includes unplanned interruptions, even those for which the distribution company is not responsible (e.g., due to transmission network outages), and also planned interruptions (e.g., to accommodate extensions, upgrades, etc.). We do not exclude, as it usually done for regulatory purpose, outages due to exceptional events, as we believe that the distinction is rather artificial. Nevertheless, we include the percentage of exceptional events as an environmental factor (on average $11 \%$ of the interruptions are labelled as exceptional) to take into account unobserved heterogeneity across centres such as different weather conditions.

\section{Environmental factors}

The estimated production technology is (implicitly) assumed to be potentially different for each DSOs and each period. To take into account local variations across DSOs and time, we introduce a number of environmental factors in the production function as regressors. ${ }^{13}$ We thus have an extended distance function that take into account of 
differences between DSOs that are not linked to inputs and outputs but to specific local conditions.

The variables that we consider are as follows (for each variable, the expected sign is reported into brackets):

- UNDERG $(+)$ is the proportion of the network that is located underground (as opposed to being overhead on poles). We expect that the higher asset values for underground lines in CAP will be offset by the reduced maintenance requirements in OPEX and the reduced number of outages. However, there may be some other aspect to undergrounding that we have not captured in our model, and hence we include this variable to see if we can identify an additional effect.

- DENSE (-) is the proportion of customers that are located in towns involving less than 10,000 inhabitants. Centres deserving a higher proportion of rural areas are potentially facing less favourable production conditions.

- AGE $( \pm)$ is the ratio of net book value to gross book value of assets. Hence it is an index of average asset age that varies between 0 and 1, with higher values indicating newer assets. The expected effect on the production technology is ambiguous. On the one hand, DSOs with older assets are using a less reliable technology but, on the other hand, DSOs with newer assets face adjustment costs.

- HVCON (+) is the amount of high voltage capacity that is contracted to industrial customers divided by total transformer potential. It is an indicator of the degree to which industrial customers are important to the DSO. A higher proportion of potential industrial demand would probably affect, ceteris paribus, positively the production technology.

We consider that the production function is time-invariant. But electricity consumption and input uses, mainly outages and repairs, could be affected by changes in the demand and in weather conditions, included exceptional events. To take this into account, we incorporate the following context variables:

- D2004 ( \pm ) and D2005 ( \pm ) are dummy variables that attempt to capture factors that vary from one year to another, such as the effects of temperature variations on demand patterns and the effects of storm events on outages. 
- EXNINT (-) is the proportion of NINT that is due to exceptional events.

- EXMINT (-) is the proportion of MINT (minutes of interruptions) that is due to exceptional events.

- GROWTH (-) is the ratio of customer numbers in the current year to customer numbers in the previous year. Important positive (negative) variations in the number of customers could potentially affect, negatively (positively), the production environment of a centre given high adaptation costs.

\section{Descriptive statistics}

We have access to a unique and comprehensive database covering 92 French DSOs (nearly all the DSOs in France) during a three-year period. All the DSOs have the same perimeter of activities and data are provided by a single source. The units of observation are the 92 ERDF centres (Paris is not included in this study). All the values reported in the tables are averages for the three-year period 2003-2005. Table 1 provides an overview of outputs, inputs and environmental factors. It illustrates the range of variation among centres, not only on size, measured by the number of residential customers and the surface served, but particularly in terms of the share of underground lines and of small towns, as well as the percentage of outages, frequency and duration, due to exceptional events. 
Table 1: Output and input variables. Descriptive statistics $(n=276)$

\begin{tabular}{|l|r|r|r|r|r|}
\hline \multicolumn{1}{|c|}{ Variable } & Units & mean & std & min & \multicolumn{1}{c|}{$\max$} \\
\hline Outputs & & & & & \\
Customers (CUST) & $\mathrm{N}$ & 324,857 & 134,162 & 109,435 & 762,905 \\
Surface (KM2) & $\mathrm{km}^{2}$ & 5,532 & 3,125 & 129 & 13,871 \\
Electricity (GWH) & $\mathrm{GWh}$ & 3,557 & 1,477 & 1,001 & 7,976 \\
Inputs & & & & & \\
Operational expenditures (OPEX) & $10^{3} €$ & 22,804 & 8,401 & 10,575 & 57,591 \\
Capital (CAP) & $10^{3} €$ & 636,134 & 220,018 & 247,464 & $1,250,115$ \\
Number of interruptions (NINT) & $\mathrm{n}$ & 384,476 & 204,569 & 48,886 & $1,632,336$ \\
Environmental factors & & & & & \\
Underground lines (UNDERG) & ratio & 0.39 & 0.19 & 0.13 & 0.88 \\
Small towns (DENS) & ratio & 0.44 & 0.23 & 0.00 & 0.86 \\
Assets age proxy (AGE) & ratio & 0.62 & 0.03 & 0.53 & 0.68 \\
Customers growth (GROWTH) & $\%$ & 1.97 & 1.81 & -5.46 & 19.97 \\
HV industrial capacity (HVCO) & ratio & 0.24 & 0.06 & 0.14 & 0.42 \\
Exceptional events: & & & & & 0.49 \\
- Frequency (EXNINT) & ratio & 0.11 & 0.11 & 0.00 & 0.00 \\
- Minutes (EXMINT) & ratio & 0.13 & 0.18 & 0.82 \\
\hline
\end{tabular}

Note: $€ 2005$ prices.

Table 2 presents ratios of output and input quantities reported across the customer density (CUST/KM2) quintiles. Depending on customer density, input and output mixes vary notably. On the one hand, electricity consumption per customer (GWH/CUST) is on average invariant across quintiles but, as expected, capital density (CAP/KM2) varies substantially across the customer density quintiles. ${ }^{14}$ On the other hand, operational costs per customer (OPEX/CUST) diminishes from $91.4 €$ to $58.9 €$ from the first to the fifth quintiles, while the frequency of interruptions (SAIFI=NINT/CUST) varies in a similar manner, being close to 1.53 per customer per year among centres in the low density quintile and close to 0.97 in the highest quintile. ${ }^{15}$ Finally centres in low-density areas have relatively more lines on poles and less underground lines.

Table 2: Production characteristics

\begin{tabular}{|c|c|c|c|c|c|c|}
\hline \multirow{3}{*}{$\begin{array}{c}\text { Customers' } \\
\text { density } \\
\text { quintile }\end{array}$} & \multicolumn{2}{|c|}{ Outputs ratios } & \multicolumn{3}{|c|}{ Input / Output ratios } & \multirow{3}{*}{$\begin{array}{l}\text { Underground } \\
\text { lines } \\
(\%)\end{array}$} \\
\hline & CUST & GWH & OPEX & CAP & NINT & \\
\hline & $\overline{\mathrm{KM} 2}$ & $\overline{\text { CUST }}$ & $\overline{\text { CUST }}$ & $\overline{\mathrm{KM} 2}$ & $\overline{\text { CUST }}$ & \\
\hline Q1 & 23.0 & 11.0 & 91.4 & 63.9 & 1.53 & 22.4 \\
\hline Q2 & 36.3 & 12.2 & 77.6 & 84.5 & 1.27 & 27.6 \\
\hline Q3 & 55.5 & 12.2 & 73.4 & 118.4 & 1.33 & 32.6 \\
\hline Q4 & 88.2 & 11.9 & 67.7 & 163.9 & 1.05 & 42.1 \\
\hline Q5 & $1,223.0$ & 10.6 & 58.9 & $1,384.0$ & 0.97 & 69.6 \\
\hline Mean & 288.6 & 13.1 & 73.7 & 366.7 & 1.23 & 39.0 \\
\hline
\end{tabular}

Customers' density quintiles: 0-30 (Q1), 30-46 (Q2); 46-71 (Q3); 71-114 (Q4) and 114 and + (Q5). 


\section{RESULTS}

In this section we report the parameter estimates and the technical efficiency (TE) scores obtained using Stochastic Frontier Analysis (SFA) and Parametric Linear Programming (PLP) with monotonicity restrictions imposed. Finally, we report partial elasticities and quality shadow prices computed for the PLP model.

Table 3 presents parameters of the distance function for both the SFA and the PLP models. Note that output $\left(y_{m}, m=1, \ldots, M\right)$ and input $\left(x_{k}, k=1, \ldots, K\right)$ variables are in logarithms and also in deviations with respect to means and environmental factors $\left(z_{j}\right.$, $j=1, \ldots, J)$ in deviations with respect to means, except for dummy variables $\left(z_{1}\right.$ and $\left.z_{2}\right)$. In the SFA model, $x_{1}$ was chosen as the reference variable to impose homogeneity of degree $+1 .{ }^{16}$ Therefore, $x_{1}$ becomes the dependent variable and $x_{k}$ are replaced by $x^{*}{ }_{k}=x_{k}-x_{1}$ for $k$ $=2, \ldots k$.

Note that $y_{1}=\mathrm{CUST} ; y_{2}=\mathrm{KM} 2 ; y_{3}=\mathrm{GWH} ; x_{1}=\mathrm{OPEX} ; x_{2}=\mathrm{CAP} ; x_{3}=\mathrm{NINT}$.

Given that these variables are expressed in logarithmic deviations from mean values, first order coefficients associated with outputs and inputs may be interpreted as distance function elasticities with respect to outputs and inputs at the sample mean, respectively. In both models these coefficients have the expected sign, negative for outputs elasticities $\left(r_{m i}\right)$ and positive for inputs $\left(s_{k i}\right)$, and are close each other. Under the SFA model, in most cases these coefficients are statistically significant at the $1 \%$ confidence level, except for the coefficient of the quality variable $\left(x_{3}=\right.$ NINT). Second order terms are significant for the squared capital variable ( $\left.x_{2}=\mathrm{CAP}\right)$, the squared quality variable $\left(x_{3}=\right.$ NINT) and for the squared customer output ( $y_{1}=$ CUST), but insignificant for most of the other terms. The coefficients reported in Table 3 show close results between SFA and PLP models at mean sample values. That is, independent of their stochastic and deterministic nature, the extended distance function estimates are quite similar. However, the SFA estimates do not always satisfy monotonicity properties at all points, as PLP does. ${ }^{17}$ 
Table 3: SFA and PLP coefficients

\begin{tabular}{|c|c|c|c|}
\hline \multirow{2}{*}{\multicolumn{2}{|c|}{ Explanatory variables }} & \multirow{2}{*}{$\frac{\text { SFA }}{\text { Coef. (t-ratio) }}$} & \multirow{2}{*}{$\frac{\text { PLP }}{\text { Coef. }}$} \\
\hline & & & \\
\hline$\alpha_{0}$ & Intercept & $0.491(2.5)^{* * *}$ & 0.754 \\
\hline$\alpha$ & $\ln \left(\mathrm{y}_{1}\right)(\mathrm{CUST})$ & $-0.759(-16.0)^{* * *}$ & -0.683 \\
\hline$\alpha_{2}$ & $\ln \left(\mathrm{y}_{2}\right)(\mathrm{KM} 2)$ & $-0.055(-2.8)^{* * *}$ & -0.051 \\
\hline$\alpha_{3}$ & $\ln \left(\mathrm{y}_{3}\right)(\mathrm{GWH})$ & $-0.147(-3.3)^{* * *}$ & -0.254 \\
\hline$\alpha_{1}$ & $\ln \left(\mathrm{y}_{1}\right) \cdot \ln \left(\mathrm{y}_{1}\right)$ & $0.983(2.0)^{* *}$ & 0.358 \\
\hline$\alpha_{22}$ & $\ln \left(\mathrm{y}_{2}\right) \cdot \ln \left(\mathrm{y}_{2}\right)$ & $0.022(1.7)^{*}$ & 0.004 \\
\hline$\alpha_{3: 3}$ & $\ln \left(\mathrm{y}_{3}\right) \cdot \ln \left(\mathrm{y}_{3}\right)$ & $0.197 \quad(0.4)$ & 0.132 \\
\hline$\alpha_{12}$ & $\ln \left(\mathrm{y}_{1}\right) \cdot \ln \left(\mathrm{y}_{2}\right)$ & $0.022(0.4)$ & -0.085 \\
\hline$\alpha_{13}$ & $\ln \left(\mathrm{y}_{1}\right) \cdot \ln \left(\mathrm{y}_{3}\right)$ & $-0.652 \quad(-1.4)$ & -0.258 \\
\hline$\alpha_{3}$ & $\ln \left(\mathrm{y}_{2}\right) \cdot \ln \left(\mathrm{y}_{3}\right)$ & $0.115(2.1)^{* *}$ & 0.121 \\
\hline$\beta$ & $\ln \left(\mathrm{x}_{1}\right)(\mathrm{OPEX})$ & $\underline{0.501}$ & 0.587 \\
\hline$\beta_{2}$ & $\ln \left(\mathrm{x}_{2}\right)(\mathrm{CAP})$ & $0.467(9.7)^{* * *}$ & 0.308 \\
\hline$\beta_{3}$ & $\ln \left(\mathrm{x}_{3}\right)(\mathrm{NINT})$ & $0.032(1.5)$ & 0.105 \\
\hline$\beta_{\text {in }}$ & $\ln \left(\mathrm{x}_{1}\right) \cdot \ln \left(\mathrm{x}_{1}\right)$ & -0.821 & -0.479 \\
\hline$\beta_{22}$ & $\ln \left(\mathrm{x}_{2}\right) \cdot \ln \left(\mathrm{x}_{2}\right)$ & $-0.890(-3.4)^{* * *}$ & -0.406 \\
\hline$\beta_{3 s}$ & $\ln \left(x_{3}\right) \cdot \ln \left(x_{3}\right)$ & $-0.164(-2.3)^{* *}$ & -0.078 \\
\hline$\beta_{12}$ & $\ln \left(\mathrm{x}_{1}\right) \cdot \ln \left(\mathrm{x}_{2}\right)$ & $\underline{0.773}$ & 0.404 \\
\hline$\beta_{13}$ & $\ln \left(\mathrm{x}_{1}\right) \cdot \ln \left(\mathrm{x}_{3}\right)$ & $\underline{0.048}$ & 0.076 \\
\hline$\beta_{s}$ & $\ln \left(\mathrm{x}_{2}\right) \cdot \ln \left(\mathrm{x}_{3}\right)$ & 0.117 ( 1.1$)$ & 0.003 \\
\hline$\delta_{w}$ & $\ln \left(\mathrm{x}_{1}\right) \cdot \ln \left(\mathrm{y}_{1}\right)$ & $\underline{-0.233}$ & 0.119 \\
\hline$\delta_{12}$ & $\ln \left(\mathrm{x}_{1}\right) \cdot \ln \left(\mathrm{y}_{2}\right)$ & $\underline{0.049}$ & 0.056 \\
\hline$\delta_{3}$ & $\ln \left(\mathrm{x}_{1}\right) \cdot \ln \left(\mathrm{y}_{3}\right)$ & $\underline{0.210}$ & -0.206 \\
\hline$\delta_{2}$ & $\ln \left(\mathrm{x}_{2}\right) \cdot \ln \left(\mathrm{y}_{1}\right)$ & $0.201 \quad(0.7)$ & -0.031 \\
\hline$\delta_{22}$ & $\ln \left(\mathrm{x}_{2}\right) \cdot \ln \left(\mathrm{y}_{2}\right)$ & $-0.062 \quad(-1.6)$ & -0.071 \\
\hline$\delta_{23}$ & $\ln \left(\mathrm{x}_{2}\right) \cdot \ln \left(\mathrm{y}_{3}\right)$ & $-0.174 \quad(-0.7)$ & 0.141 \\
\hline$\delta_{\mathrm{s}}$ & $\ln \left(\mathrm{x}_{3}\right) \cdot \ln \left(\mathrm{y}_{1}\right)$ & $0.032(0.2)$ & -0.088 \\
\hline$\delta_{32}$ & $\ln \left(\mathrm{x}_{3}\right) \cdot \ln \left(\mathrm{y}_{2}\right)$ & $0.013(0.7)$ & 0.015 \\
\hline$\delta_{33}$ & $\ln \left(\mathrm{x}_{3}\right) \cdot \ln \left(\mathrm{y}_{3}\right)$ & $-0.036 \quad(-0.3)$ & 0.064 \\
\hline \multicolumn{4}{|c|}{ Environmental factors } \\
\hline$\theta$ & $\mathrm{z}_{1}$ (UNDERG) & $0.236(7.0)^{* * *}$ & 0.186 \\
\hline$\theta_{2}$ & $\mathrm{z}_{2}$ (DENSE) & $-0.040 \quad(-1.2)$ & -0.023 \\
\hline$\theta_{s}$ & $\mathrm{z}_{3}(\mathrm{AGE})$ & $-0.608(-3.2)^{* * *}$ & -0.888 \\
\hline$\theta$ & $\mathrm{z}_{4}(\mathrm{HVCON})$ & $0.033(1.1)$ & 0.107 \\
\hline$\theta_{s}$ & $z_{5}(D 2004)$ & $-0.015 \quad(-1.1)$ & 0.009 \\
\hline$\theta$ & $\mathrm{z}_{6}(\mathrm{D} 2005)$ & $0.081(4.8)^{* * *}$ & 0.127 \\
\hline$\theta$ & $\mathrm{z}_{7}(\mathrm{EXNINT})$ & $-0.005 \quad(-0.6)$ & -0.013 \\
\hline$\theta_{s}$ & z8 (EXMINT) & $0.004(0.6)$ & -0.002 \\
\hline$\theta$ & $\mathrm{z}_{9}$ (GROWTH) & $-0.006 \quad(-0.9)$ & 0.006 \\
\hline$\sigma$ & $\sqrt{\sigma_{u}^{2}+\sigma_{v}^{2}}$ & $0.015(4.4)^{* * *}$ & \\
\hline$\gamma$ & $\sigma_{u}^{2} /\left(\sigma_{u}^{2}+\sigma_{v}^{2}\right)$ & $0.745(5.0)^{* * *}$ & \\
\hline & LLF & 286.0 & \\
\hline
\end{tabular}

***, ${ }^{* *}$ and ${ }^{*}$ significant at $1 \%, 5 \%$ and $10 \%$ level, respectively. Underlined parameters are calculated by applying the homogeneity conditions. Variables $\ln \left(\mathrm{y}_{\mathrm{m}}\right)$ and $\ln \left(\mathrm{x}_{\mathrm{k}}\right)$ are expressed in deviations from sample mean values. 


\section{Environmental factors}

Of the environment factors ( $z_{j}$ variables), we observe that under the SFA and the PLP model results are quite similar. Moreover, under the SFA model DENSE $\left(\mathrm{z}_{2}\right), \operatorname{HVCON}\left(\mathrm{z}_{3}\right)$, D2004 ( $\left.\mathrm{z}_{5}\right)$, EXNINT ( $\left.\mathrm{z}_{7}\right)$, EXMINT ( $\left.\mathrm{z}_{8}\right)$ and GROWTH (z9), are statistically insignificant (at the 5\% level). UNDERG $\left(\mathrm{z}_{1}\right), \operatorname{AGE}\left(\mathrm{z}_{3}\right)$ and D2005 $\left(\mathrm{z}_{6}\right)$ are the only variables that are significant.

The coefficient of UNDERG (percentage of underground lines) is positive. As expected, this factor has a positive effect on production performances, because underground lines are less susceptible to storm damage, etc.

The coefficient of AGE (the ratio of net (depreciated) to gross capital in book values) is negative. As indicated before, the expected effect of this factor on production technology was ambiguous. Likely, adjustment costs, "teething problems", associated with newer assets exceed advantages in terms of lower maintenance costs. Finally, year 2005 has a positive sign and D2005 is significant at the 1\% level. The Centres could be improving their productivity by making a better input use (technical change). But, unfortunately, with a limited time frame, we cannot screen between permanent (better management) and temporary effects (weather conditions) even though, as indicated before, the effect of outages due to exceptional events (EXNINT and EXMINT) appear to be non-significant.

\section{Technical Efficiency (TE)}

In the SFA model $\gamma=0.745$ implies that the error term is primarily associated with technical efficiency. ${ }^{18}$ Table 4 reports average technical efficiency (TE) scores for the SFA and PLP models by quintiles of customers' density, quality (SAIFI) and underground lines (\%). As expected, SFA technical efficiency scores are higher than PLP scores, 0.922 vs. 0.864 on average. This is due to the role played by noise under the SFA model, as indicated before. The Pearson correlation between the two sets of scores is 0.80 .

Similar slight variations are observed for both measures; decreasing technical efficiency with customers density and the proportion of underground lines, while increasing with quality levels. 
In order to identify these relationships among inputs, we turn now to a deeper study of the underlying production technology, looking at distance function elasticities and shadow prices at all points (92 Centres, 3 years). For this purpose, we rely exclusively on PLP results. Unfortunately, but as expected, the estimated SFA technology did not satisfy all monotonicity restrictions at all data points. ${ }^{19}$

Table 4: SFA and PLP Technical Efficiency scores by quintiles

\begin{tabular}{|c|c|c|c|c|c|c|}
\hline \multirow{2}{*}{ Quintiles } & \multicolumn{3}{|c|}{ SFA } & \multicolumn{3}{c|}{ PLP } \\
\cline { 2 - 7 } & $\begin{array}{c}\text { Customers' } \\
\text { density } \\
\text { quintiles }\end{array}$ & $\begin{array}{c}\text { Quality } \\
\text { quintiles } \\
\text { (SAIFI) }\end{array}$ & $\begin{array}{c}\text { Underground } \\
\text { lines } \\
\text { quintiles }\end{array}$ & $\begin{array}{c}\text { Customers' } \\
\text { density } \\
\text { quintiles }\end{array}$ & $\begin{array}{c}\text { Quality } \\
\text { quintiles } \\
\text { (SAIFI) }\end{array}$ & $\begin{array}{c}\text { Underground } \\
\text { lines } \\
\text { quintiles }\end{array}$ \\
\hline Q1 & 0.924 & 0.909 & 0.923 & 0.890 & 0.846 & 0.888 \\
Q2 & 0.923 & 0.925 & 0.927 & 0.863 & 0.859 & 0.869 \\
Q3 & 0.927 & 0.927 & 0.925 & 0.867 & 0.882 & 0.856 \\
Q4 & 0.925 & 0.923 & 0.916 & 0.859 & 0.867 & 0.854 \\
Q5 & 0.909 & 0.924 & 0.918 & 0.840 & 0.866 & 0.853 \\
\hline All & 0.922 & 0.922 & 0.922 & 0.864 & 0.864 & 0.864 \\
\hline
\end{tabular}

Customers' density quintiles: 0-30 (Q1), 30-46 (Q2); 46-71 (Q3); 71-114 (Q4) and 114 and + (Q5). Quality quintiles (SAIFI): 1.9+ (Q1); 1.9-1.5 (Q2); 1.5-1.26 (Q3); 1.26-1.0 (Q4); 1.0-0.0 (Q5).

Underground lines quintiles: 0-0.23 (Q1), 0.23-0.30 (Q2); 0.30-0.37 (Q3); 0.37-0.52 (Q4) and 0.52+ (Q5).

\section{Input and output distance function elasticities (PLP)}

Table 5 contains information on distance function elasticities with respect to inputs $\left(s_{k i}\right)$ and outputs $\left(r_{m i}\right)$. They are computed using equations (9) and (10) and correspond to input shares and to output shares, respectively. Output elasticities contain useful information on the cost drivers of the DSOs and the scale economies. For the stake of clarity, we consider output elasticities in absolute value. At the aggregate level, the estimated output elasticities (with the PLP method) are 0.683 for CUST, 0.052 for KM2 and 0.256 for GWH meaning that, a $10 \%$ increase in the number of clients, in the surface covered or in the electricity distributed requires respectively a $6.8 \%, 0.5 \%$ and $2.5 \%$ proportional increase of all inputs. Thus, for an average DSO, the main cost driver is the number of clients. And, should all outputs increase proportionally, the input expansion required would be less than proportional as $e_{i}=\Sigma_{i} r_{m i}=-0.988>-1$, implying increasing returns to scale for the average firm..$^{20}$

In Table 5, we report the input and output elasticities by customers' density quintiles. Input combinations and use differ with customer density (see Table 2) and low-density centres have a higher percentage of underground lines. Interestingly, the distance 
function elasticities with respect to the number of customers decrease with density while, simultaneously, surface elasticities and most notably energy distributed elasticities increase. For centres in high-density areas, the main cost drivers are the electricity distributed with a partial elasticity equals to 0.547 for the DSO in the fifth quintile of customer density and the number of clients with a partial elasticity of GWH equal to 0.472 . Conversely, for the centres operating in low-density areas, increasing the electricity distributed requires a lower input expansion with a partial elasticity of GWH equal to 0.102 in the first quintile of customer density. Existing networks are thus able to carry on additional electricity flows at low cost in the low-density regions, while in high-density regions, additional flows require a substantial input expansion. And conversely, it is relatively less costly to connect an additional customer in a high-density region because the network is dense and connections are numerous than in a lowdensity region. To summarize, the main cost driver in low-density areas is the number of customers. In high-density areas, both the number of clients and the electricity distributed are the most significant cost drivers of the DSO. Taking the sum of partial elasticities, in the estimated production function, the scale elasticities go from increasing returns in low-density units to decreasing returns in high-density units ${ }^{21}$.

Table 5: Distance function elasticities (PLP)

\begin{tabular}{|c|c|c|c|c|c|c|c|}
\hline \multirow{2}{*}{$\begin{array}{c}\text { Customers' } \\
\text { density } \\
\text { quintiles }\end{array}$} & \multicolumn{3}{|c|}{$\begin{array}{l}\text { With respect to inputs } \\
\text { "input shares" }\end{array}$} & \multicolumn{3}{|c|}{$\begin{array}{l}\text { With respect to outputs } \\
\text { "output shares" }\end{array}$} & \multirow{2}{*}{$\begin{array}{l}\text { Scale } \\
\text { elasticity }\end{array}$} \\
\hline & $\begin{array}{l}\text { Operational } \\
\text { costs } \\
\text { (OPEX) }\end{array}$ & $\begin{array}{l}\text { Capital } \\
\text { (CAP) }\end{array}$ & $\begin{array}{l}\text { Quality } \\
\text { (NINT) }\end{array}$ & $\begin{array}{l}\text { Customers } \\
\text { (CUST) }\end{array}$ & $\begin{array}{l}\text { Surface } \\
\text { (KM2) }\end{array}$ & $\begin{array}{c}\text { Electricity } \\
\text { distributed } \\
(\mathrm{GWH})\end{array}$ & \\
\hline Q1 & 0.719 & 0.161 & 0.123 & -0.785 & -0.079 & -0.102 & -0.963 \\
\hline Q2 & 0.648 & 0.230 & 0.122 & -0.767 & -0.051 & -0.145 & -0.963 \\
\hline Q3 & 0.622 & 0.275 & 0.103 & -0.729 & -0.043 & -0.198 & -0.970 \\
\hline Q4 & 0.556 & 0.336 & 0.107 & -0.668 & -0.042 & -0.276 & -0.985 \\
\hline Q5 & 0.402 & 0.534 & 0.073 & -0.472 & -0.043 & -0.547 & -1.062 \\
\hline Mean & 0.589 & 0.309 & 0.106 & -0.683 & -0.052 & -0.256 & -0.988 \\
\hline
\end{tabular}

Customers' density quintiles: 0-30 (Q1), 30-46 (Q2); 46-71 (Q3); 71-114 (Q4) and 114 and + (Q5).

Regarding distance function elasticities with respect to inputs, we observe that the share of OPEX decreases with customer's density while the share of CAP increases. Output expansion requires relatively more capital in high-density areas and relatively more operational expenditures in low-density areas. The input share of quality is 
comparatively low, on average equal to $10.6 \%$, and decreasing slightly with costumers' density.

The shadow price of quality (PLP)

Using the estimated production function (with the PLP method to satisfy all the monotonicity restrictions), we can identify, for each observation, the input and output shadow price ratios. We are particularly interested in the input shadow price ratios NINT/OPEX and NINT/CAP. These shadow price ratios can be converted into a shadow price of quality by assuming a particular observed price for OPEX or CAP. For OPEX, the observed price is trivially equal to $1 €$. The price of capital is more difficult to estimate, since it requires assumptions regarding depreciation and interest costs. Hence we will focus on the shadow price estimate obtained from the NINT/OPEX shadow price ratio.

In our sample, the average shadow price of quality (in OPEX) is equal to $10.7 €$. This means that, in average, the DSO must spend an extra $10.7 €$ in operational expenditure to prevent one interruption or, as the mean interruption time is 59 minutes, it costs $0.181 €$ to prevent one minute of interruption. ${ }^{22}$ Multiplying by the number of customers, the cost of avoiding one minute of interruption across all customers is estimated at 5.5 million €.

Starting in 2009, the French regulator put in place an incentive scheme for quality of electricity distribution. Any additional minute of interruption above (below) the quality threshold induces a penalty (reward). The penalty for an extra minute of interruption across all customers is set at 4 million $€$ (3.89 millions $€$ if expressed in 2005 price), with the total penalty capped at 50 million $€$. Based on that, we estimate that the regulated (marginal) price of quality is equal to $0.1264 €$ per minute (in 2005 price). The estimated cost of quality (from our PLP results using sample data for the period 200305) is slightly higher than the regulated price (applicable as from 2009). For the UK, Jamasb et al. (2010) estimate that the regulated price is (far) below the cost of increasing quality. Accordingly, such an incentive system fails to provide incentives for quality improvements. 
The shadow price of quality is not uniform across centres: the computed shadow price values vary from $1.8 €$ to $69.2 €$. Shadow price levels mainly depend on the quality itself. More reliable networks tend to have a higher marginal cost of improving quality. This is nicely illustrated in Figure 2. The horizontal axis corresponds to quality (SAIFI) and the dots to the ERDF units (92 Centres, average values over the three year period analysed). Thus, as one would expect, marginal quality improvements tend to be more expensive as a distribution network approaches $100 \%$ reliability. Improving quality thus implies a convex cost relationship. 
Figure 2: Quality shadow price (PLP)

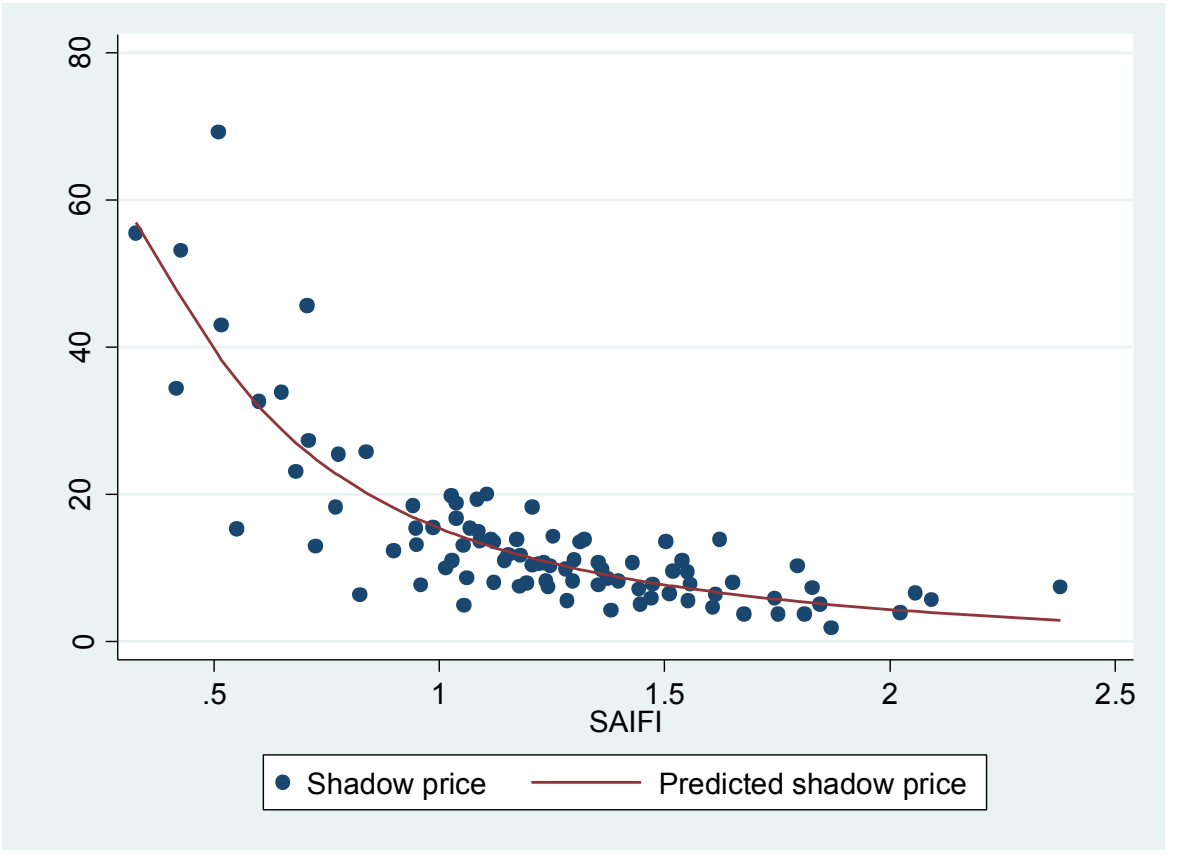

Note: Mean values by Centre over the 2003 to 2005 period.

This is again apparent if one looks at the shadow prices of quality across quality quintiles in Table 6. Low quality Centres (first quintile) have a shadow price of $5.3 €$ in OPEX price and of $404.9 €$ in Capital price, while those with high quality (fifth quintile) have higher shadow prices of $26.9 €$ and $686.5 €$, respectively.

Table 6: Shadow price ratios ( $€ 2005$ prices)

\begin{tabular}{|c|r|c|}
\hline $\begin{array}{c}\text { Quality } \\
\text { quintiles }\end{array}$ & $\begin{array}{c}\text { Quality } \\
\text { OPEX }\end{array}$ & $\begin{array}{c}\text { Quality } \\
\text { Capital }\end{array}$ \\
\hline Q1 & 5.3 & 404.9 \\
Q2 & 8.5 & 612.8 \\
Q3 & 10.8 & 717.3 \\
Q4 & 13.1 & 634.1 \\
Q5 & 26.9 & 686.5 \\
\hline All & 10.7 & 568.3 \\
\hline
\end{tabular}

Quality quintiles (SAIFI): 1.9+ (Q1); 1.9-1.5 (Q2); 1.5-1.26 (Q3); 1.26-1.0 (Q4); 1.0-0.0 (Q5).

\section{CONCLUDING REMARKS}

Electricity distribution utilities are expected to provide power to customers 24/24 hours every day of the year. To prevent outages and their related costs operators have the possibility to increase either maintenance costs or to make new investments. 
Therefore, there is an implicit cost associated with customers' interruptions (and outages duration) in terms of operational costs (OPEX) and capital investments.

In this paper, we estimate the implicit cost of outages for the 92 DSO (Centres) of ERDF, the main distribution company in France, over the period 2003-05. For this purpose, we rely on a parametric distance function approach taking the number of customers' interruptions over a year as a third input variable (along with OPEX and capital). This approach allows us to estimate and to compare production performances and to have a better understanding of the underlying production technology. The production frontier provides information on the marginal rate of technical substitution between inputs (the shadow price), and we are particularly interested in the implicit price of quality improvement. In our estimate, the shadow price of quality in OPEX price ranges from $1.8 €$ to $69.2 €$. And, as expected, the marginal cost of quality varies with quality delivered (SAIFI), implying convex costs of quality.

Nowadays, electricity regulators introduce explicit reward and penalty scheme to regulate the quality of electricity distribution. The schemes aim at promoting efficient delivery of service quality by the DSOs. For that, it is of prime importance to have a precise knowledge of the underlying production technology. Indeed, the welfare maximizing level of service quality is such that the marginal benefit of quality is equal to the marginal cost (Sappington, 2005). The consumer's valuation of quality can be constructed by specifying a price for the electricity that it is not delivered (see Fumagalli et al., 2007) but the marginal cost of quality is more difficult to assess. Thanks to a very comprehensive dataset, we provide an estimate of this marginal cost.

As from 2009, the French regulator introduced an explicit regulation of quality, it would be interesting to compare the regulated price of quality with its marginal cost to know whether the regulatory scheme in place is likely to be effective in promoting quality improvements (unlike the UK scheme according to Jamasb et al., 2010). According to our estimates, the average shadow price for the period 2003-05, was 33\% higher than the regulated price in 2009. But, to compare the like with the like, it would be interesting to replicate our methodology with more recent data. 


\section{REFERENCES}

Battese, G.E. and Coelli, T.J., 1995. A model for technical efficiency effects in a stochastic frontier production function for panel data. Empirical Economics 20, 325-332.

Coelli, T.J., Prasada Rao, D.S., O’Donnell, C.J. and Battese, G.E., 2005. An Introduction to Efficiency and Productivity Analysis, $2^{\text {nd }}$ Edition, Springer, New York

Coelli, T.J., Crespo, H., Plagnet, M.-A., Perelman, S., Romano, E., 2007. Incorporating quality of service in a benchmarking model: an application to French electricity distribution operators. CIRED, Vienna, 21-24 May 2007 Conference Proceedings.

Coelli, T.J., Perelman, S., 1996. Efficiency measurement, multiple-output technologies and distance functions: With application to European railways. CREPP Working Paper 96/05, University of Liege.

Coelli, T.J., Perelman, S., 1999. A comparison of parametric and non-parametric distance functions: With application to European railways. European Journal of Operational Research, 117, 326-339.

Coelli, T.J., Perelman, S. and E. Romano, 1999. Accounting for environmental influences in stochastic frontier models: With application to international airlines. Journal of Productivity Analysis 11, 251-274.

Coelli, T.J., Estache, A., Perelman, S., Trujillo, L., 2003. A Primer on Efficiency Measurement for Utilities and Transport Regulators. World Bank Publications.

Edvardsen, D.F., Forsund, F.R., Hansen, W., Kittelsen, S.A.C., Neurauter, T., 2006. Productivity and Regulatory Reform of Norwegian Electricity Distribution Utilities. in Coelli, T.J., Lawrence D. (eds). Performance Measurement an Regulation of Network Utilities, Edward Elgar, Cheltelham, UK, pp. 97-131.

Färe, R., Grosskopf, S., Lovell, K. C. A., Yaisawarng, S., 1993. Derivation of Shadow Prices for Undesirable Outputs: A Distance Function Approach. The Review of Economics and Statistics, 75, 374-380. 
Färe, R., Primont, D., 1995. Multi-Output Production and Duality: Theory and Applications. Kluwer Academic Publishers, Bostom, MA.

Farsi, M., Fetz, A., Filippini, M., 2007. Benchmarking and Regulation in the Electricity Distribution Sector. CEPE Working Paper No. 54, ETH Zurich, Switzerland

Giannakis, D., Jamasb, T., Pollitt, M., 2005. Benchmarking and Incentive Regulation of Quality of Service: An Application to the UK Electricity Distribution Utilities. Energy Policy, 33, 2256-2271.

Grosskopf, S., K. Hayes, Hirschberg, J., 1995. Fiscal Stress and the Production of Public Safety: A Distance Function Approach. Journal of Public Economics, 57, 277-296.

Growitsch, C., T. Jamasb, Pollitt, M., 2009. Quality of service, efficiency and scale in network industries: An analysis of European electricity distribution. Applied Economics, $41,2555-2570$.

Fumagalli, E., Lo Schiavo, L., Delestre, F., 2007. Service quality regulation in electricity distribution and retail. Springer-Verlag Berlin Heidelberg.

Jamasb, T., Pollitt, M., 2001. Benchmarking and regulation: international electricity experience. Utilities Policy, 9, 107-130.

Jamasb, T., Orea, L., Pollitt M., 2010. Estimating Marginal Cost of Quality Improvements: The Case of the UK Electricity Distribution Companies. EPRG Working Paper 1027, University of Cambridge UK.

Korhonen, P., Syrjänen, M., 2003. Evaluation of Cost Efficiency in Finnish Electricity Distribution. Annals of Operations Research, 121, 105-122.

Lawrence, D., Diewert, E., 2006. Regulating Electricity Networks: The ABC of Setting X in New Zealand. in Coelli, T.J., Lawrence, D. (eds.). Performance Measurement and Regulation of Network Utilities. Edward Elgar Publishing, Cheltenham, pp. 207-237.

London Economics, 1999. Efficiency and benchmarking study of New South Wales distribution businesses. Report commissioned by the Independent Pricing and Regulatory Tribunal (IPART) of New South Wales, http://www.iprt.net/pdf/Rp13.pdf. 
Morrison Paul, C. J., Nehring, R., 2005. Product diversification, production systems, and economic performance in U.S. agricultural production. Journal of Econometrics, 126, $525-548$.

O’Donnell, C.J., Coelli, T.J., 2005. A Bayesian approach to imposing curvature on distance functions. Journal of Econometrics, 126, 493-523.

Sappington,M., 2005. Regulating Service Quality: A Survey. Journal of Regulatory Economics, 27, 123-154. 
Acknowledgments: Former versions of this paper were presented at the XII EWEPA (European Workshop on Efficiency and Productivity Analysis, Verona, Italy, June 2011), at the $3^{\circ}$ ELAEE (Latin American Meeting of the International Association for Energy Economics, Buenos Aires, Argentina, April 2011) and at the V EFIUCO (Congreso de Eficiencia y Productividad, Cordoba, Spain, May 2011) . The authors are grateful to Ana Rodriguez, Luis Orea, Humberto Brea, David Saal and the anonymous reviewers for comments and suggestions and to EDF (Electricite de France) for financial support. The analysis contained in this paper reflects the views of the authors and may not necessarily be those of EDF.

\section{Footnotes:}

${ }^{1}$ O'Donnell and Coelli (2005) proposed a Bayesian approach which also allows imposing regularity conditions on distance function estimations. Other than the difficulties, in terms of statistical skills and computational challenges, implied by the Bayesian approach, the deterministic PLP approach is appropriate when data is of high quality; at it is the case of the homogeneous information on ERDF units studied here.

${ }^{2}$ This is also seen in a DEA study by Korhonen and Syrjänen (2003) of Finnish electricity distribution operators, where the inclusion of a TINT variable into the DEA model led to increases in technical efficiency for a number of firms. For example, see their Figure 3. However, note that these results need to be treated with caution because their DEA model did not include a capital measure, which could lead to substantial biases.

${ }^{3}$ In a previous study, Coelli et al (2007), we used an earlier version of this data set to conduct a comparison of the SFA and data envelopment analysis (DEA) approaches.

${ }^{4}$ Competition for concession contracts is not yet possible.

${ }^{5}$ See Fumagalli et al. (2007).

${ }^{6}$ System Average Interruption Frequency Index (SAIFI) and System Average Interruption Duration Index (SAIDI) indicate the average number and the average duration of interruptions (longer than 3 minutes) experienced by customer served per year, respectively.

${ }^{7}$ Note that in our application we have annual data on 92 units over a three years period. Hence we have 276 observations. Given the short time period we assume that there has been no technological progress over this period and hence pool the data as if it was a single year of data on 276 firms when estimating the production frontiers.

${ }^{8}$ Assuming that improving quality requires a proportional increases in the other inputs. Otherwise, under a non-radial (directional) distance function setting, the shadow price of quality would be lower. We would like to thank one of the reviewers for drawing our attention to this point. 
${ }^{9}$ See O'Donnell and Coelli (2005) for an application of a Bayesian approach to impose regularity conditions.

${ }^{10}$ Imposing monotonicity restrictions at each point (locally) on PLP computations we follow Färe et al. (1993). However, on the contrary of these authors who imposed restrictions on selected outputs, we impose monotonicity on all distance function derivatives simultaneously. For more details on PLP computations, see Coelli and Perelman (1999).

${ }^{11}$ We would prefer to use net electricity delivered as output instead of gross electricity distributed, but information on losses was not available for the whole sample.

12 The gross capital value is computed by ERDF using replacement values, with the exception of capital materials that have reached the end of their depreciation period (expected potential service life), in which case the gross purchase value is only adjusted for inflation.

13 The alternative would have been to introduce the environmental factors as determinants of the technical efficiency but this can only be done in the SFA model. The advantage of an empirical strategy based on an extended distance function is that two more comparable models can be estimated as both SFA and PLP distance functions include the same set of explanatory variables.

${ }^{14}$ But capital per customer (CAP/CUST) diminishes with consumer density.

15 These observations might be seen as indicating that costs are mainly driven by the level of outages. However, the distance function estimates presented later show that it is dangerous to look at a few measures in isolation, and that the relationships are much more complex. The direction and the importance of these relations will depend, among others, on the complementarity/substitutability between OPEX, capital investments and quality.

${ }^{16}$ Results are insensitive to the choice of the reference variable, as illustrated in Coelli and Perelman (1996).

${ }^{17}$ Note that the PLP model satisfies curvature conditions in most points. The estimated input distance function (1) satisfies quasi-convexity in inputs at all points and convexity on outputs on 179/276 points.

18 The distance measures derived from the estimation of input distance functions are, by definition, equal or higher than 1.0. For presentation purposes, we transform them into technical efficiency scores, with values between 0 and 1.0, by taking the reciprocal.

${ }^{19}$ For each observation, there are 6 monotonicity constraints to be satisfied. In the SFA estimation, $11.1 \%$ of these constraints are violated and, for more than half $(58.0 \%)$ of the observations, at least one constraint is not satisfied. Mainly two variables are concerned: on the output side GWH $\left(y_{3}\right)$ and on the 
input side NINT $\left(x_{3}\right)$, the two variables for which the distance function elasticities are small (close to zero) at average values.

20 Under the SFA model, average scale elasticity also corresponds to increasing returns to scale $(e=-0.961)$. PLP results are however preferred as partial elasticities measured at each point satisfy the monotonicity conditions.

${ }^{21}$ This demonstrates that the PLP model remains flexible despite the monotonicity constraints.

22 Using a different methodology, Jamasb et al. (2010) estimate that the average cost of one minute of interruption is equal to $0.251 €$ in the UK for the period 1995-2002. 